\title{
Performance Appraisal Experiences and Its Implications on Human Resource Decisions in Decentralized Health Services in Shinyanga Region, Tanzania
}

\author{
Kisumbe Lazaro Alman \\ Local Government Training Institute, Dodoma, Tanzania, \\ Department of Human Resource Management \\ E-mail: lkisumbe04@yahoo.com \\ Mashala Lameck Yusuph \\ Local Government Training Institute, Dodoma, Tanzania \\ Department of Local Government Administration and Management \\ E-mail: m_lameck@yahoo.com
}

Received: April 19, 2020 Accepted: May 15, 2020 Online published: May 25, 2020

doi:10.5296/jpag.v10i2.16870～URL: https://doi.org/10.5296/jpag.v10i2.16870

\begin{abstract}
The study investigated the Performance Appraisal Experiences and its Implications on Human Resource (HR) Decisions in the decentralized health service in Shinyanga Region, Tanzania. The region was selected because over different periods it revealed poor performance in health service delivery whose causes remained unfolded. An explanatory Survey research design with a mixed approach was employed, whereas the survey tool was used to collect data from 287 respondents. The findings revealed that even though the team performance is evaluated through the Quality Improvement Teams, the individual employee's performance is ineffectively evaluated due to the ineffective use of the Open Performance, Review and Appraisal System (OPRAS). The ineffective use of OPRAS instrument is linked to several factors including the complexity of the instrument; inadequate availability of funds to implement the set targets; shortage of the human resources in the facilities making overwhelmed by the responsibilities; the OPRAS process being time-consuming and inadequate commitment on the use of the instrument. Thus, when the individual performance is ineffectively appraised, human resource decisions such as training and compensation for
\end{abstract}


employees' performance remain uninformed, hence affecting both their quality and human resource performance. It was thus, recommended inter alia, simplification of the OPRAS instrument and customization of it to suit the health sector settings, frequent provision of training on the application of OPRAS, and linking OPRAS results with the immediate rewards to enhance employees' commitment to the instrument. Additionally, the establishment of the mechanism to enforce the use of OPRAS in assessing employees' performance in health facilities and ensuring that the appraisal results are linked to the human resource decisions are of paramount importance for improving human resource decisions and for performance improvement in health facilities.

Keywords: performance appraisal, human resource decisions, and decentralized health service

\section{Introduction}

Performance appraisal is a process of assigning a judgmental value on the performance of an employee during a given period (Werther and Davis, 1987). Haraisa (2016) documented significant positive effects of performance appraisal on innovation $(\beta=0.420$ and $\mathrm{P}<0.05)$ in a private hospital in Amman City in Jordan. Likewise, Singh (2016) reported similar results $(\beta=0.188$ and $\mathrm{P}<0.05)$ at the Debre Brehan University in Ethiopia. Bowra et al. (2012) established resembling results $(\beta=0.3460$ and $\mathrm{P}<0.001)$ in the banking sector of Pakistan. Even though the effectiveness in performance appraisal was mentioned as a contributing factor to the results, no adequate elaborations were given regarding its ingredients. Thus, it renders it difficult for other organizations to borrow the experiences in improving the performance appraisal for human resource performance improvements. On the contrary, Hameed and Mohamed (2016) established an insignificant contribution of performance appraisal on the performance of Tiruchirapalli district hospital in India. The results were associated with the failure to carry out performance appraisal in a manner to serve as a motivator for the nurses. Likewise, Shahzad et al. (2008) documented the adverse effects of performance appraisal on employees' performance in Pakistan hospitals $(\beta=-0.404$ and $\mathrm{P}<0.05)$. The results were associated with a failure to apply the merit-based performance appraisal system.

In Tanzania, decentralization was adopted in the 1990s as a part of the Local Government Reform to enhance community participation in service delivery at the respective locality (URT, 1998). The decentralization by Devolution (D-by-D) was used as a vehicle for decentralizing the financial, human, and political powers to the Local Government Authorities (LGAs). The decentralized powers at LGA level are exercisable through community representative organs including councilors, chairpersons, and committee members. The Local government at headquarters further decentralizes the powers to lower levels including health facilities. It aimed at enhancing the accountability and responsiveness of the human resources to the community at the specific locality. As a result of decentralization, human resource management was entrusted at a specific facility to deliver social services to the respective community. The Open Performance Review and Appraisal System (OPRAS) was introduced as a tool to assess employees' performance in the public service in Tanzania. It was designed in 
a way to facilitate making informed human resource decisions including training and compensation for performance improvement. However, there has been a mismatch between the OPRAS results and the actual performance in the decentralized public services in Tanzania. Most of the supervisors and supervisees in LGAs awarded high scores to avoid criticisms from subordinates and punishments for poor performance respectively (Tefurukwa, 2014).

Likewise, in 2013/2014, the Controller and Auditor General (CAG) of Tanzania found no evidence regarding the application of OPRAS instrument at Ardhi University, Tanga Urban Water Supply, Tanzania Education Authority, Ubungo Plaza, Kariakoo Market, National Institute of Transport, Institute of Social Work and Shinyanga Urban Water Supply and Sanitation Authority (CAG, 2015). Also, in 2014/2015, the CAG's audit report for two ministries and five regional secretariats documented that 64\% (119) of 187 sampled personal files lacked evidence regarding the application of the OPRAS instrument on performance evaluation (CAG, 2016). Moreover, in 2015/2016, the audit report for 36 councils in Tanzania Mainland revealed that performance evaluation of public service employees was either not undertaken at all or ineffectively undertaken (CAG, 2017). Similar results were reported in 2016/2017 (CAG, 2018) where most of the public organizations did not show evidence for the application of OPRAS in assessing employees' performance. The frequently reported ineffective use of OPRAS in both Central and LGAs is contrary to the Public Service Act of 2002, Public Service Regulations, 2003, the Standing Orders for Public Service in Tanzania, 2009 and the guideline for the application of OPRAS in public services, 2011 (URT, 2002, URT, 2003, 2009 \& URT, 2011). Likewise, the ineffective use of OPRAS was reported in the Health Strategic Plan 2008-2013 which documented that even though OPRAS was introduced in 2004 to replace the then confidential appraisal system commonly used in Tanzania Public Service, the longevity of the employees in service dominates human resource decisions (MoHSW, 2008). Nevertheless, the effects of ineffective individual performance appraisal on human resource decisions are inadequately addressed by the studies. This study, therefore, was meant to bridge this knowledge gap by adding to the existing literature regarding the performance appraisal experiences and its implications in training and compensation for employees' performance decisions in the decentralized health service in the Shinyanga region, Tanzania.

\section{Theory and Conceptual Framework}

\subsection{Theory Governing the Study}

The study was informed by the Decentralization Theorem developed by Oates in 1972. The centre of attention of the theory was to explain the fiscal decentralization based on the main assumption that in the absence of the cost savings from centralization and inter-jurisdictional externalities, fiscal responsibilities should be decentralized (Koethenbuerger, 2008; Greco, 2004). The decentralization is beneficial when preferences are highly heterogeneous across jurisdictions. In such a situation it is important to provide a social venue for community participation to identify their specific needs in the respective jurisdiction. This enhances service providers to match the service provision with community priorities for service 
improvements (Oates, 2006). Likewise, community participation leads to reduced bureaucracy, enhanced accountability, and improved innovations among service providers as a result of competition among service providers. In reducing bureaucracy, the community acts as the watchdog for resources use and their performance (Ivanyna and Shah, 2012). This reduces resource leakage and, hence, contributes to the realization of allocative efficiency (Martinez-Vazquez, 2011). Likewise, administratively, human resource is managed by the respective in-charges of the organization.

Although the theory was meant for fiscal decentralization, it suitably fits to explain the performance appraisal experiences and implications on human resource decisions in decentralized health services. This was found relevant for the study due to the health services and human resources management being decentralized at the facility level of each of the respective Local Government Authority. This is in line with the Local Government Reform introduced in the 1990s with the focus to decentralize the management of services to the LGAs established under Article 145 of the constitution of the United Republic of Tanzania of 1977. Article 146 of the constitution provides that LGAs are purposely established to facilitate community participation in the planning and implementation of development plans in their localities for service delivery improvement (URT, 2005). The Local Government Reform was guided by the Local Government Reform Policy paper of 1998 which employed decentralization by devolution (D-by-D) to enhance people's participation as stipulated in Article 146 of the constitution of the country. The policy decentralized the management of the human resource at the local government which decentralized further at the facility levels for performance improvement (URT, 1998). Thus, in the context of the health services, the human resource practices including performance appraisal, training, and compensation for performance are managed at the facility level to enhance accountability and responsiveness to the needs of the respective community they serve. Thus, with the decentralized application of the performance appraisal, it is possible to genuinely assess the performance of the employees and use the results to make appropriate decisions on training and compensation/rewards for performance improvement as illustrated in the conceptual framework.

\subsection{Conceptual Framework}

Conceptually, the decentralized performance appraisal implies that employees' performances are genuinely appraised as the supervisors and supervisees closely work together in a facility. In this perspective, the performance appraisal at the respective health facility enhances to come up with the genuine performance results of each employee as they can easily call for employees' accountability for the assigned responsibilities. The evaluation results facilitate in making informed training and compensation decisions as shown in Figure 1. 


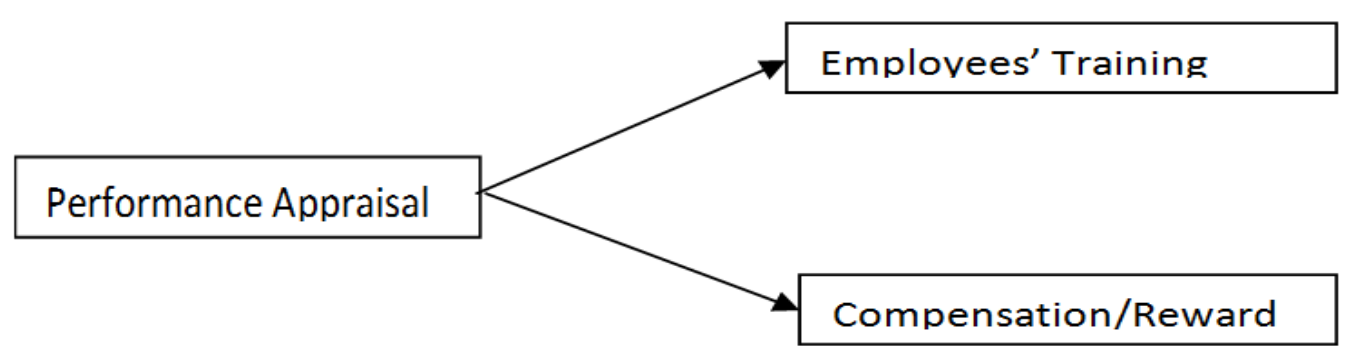

Figure 1. Conceptual Framework

Source: Researchers' Construct 2020

Thus, with the decentralized performance appraisal, it is expected to provide training based on the identified performance gaps. Likewise, the compensation for employees' performance is to be made on the meritocratic principle.

\section{Materials and Methods}

An explanatory Survey research design with a mixed approach (quantitative being dominant) was used. Shinyanga region was selected because in 2009 only $39 \%$ of the patients attended the health facility in the region. The number of patients marginally rose by $1 \%$ to $40 \%$ in 2012 (Kumalija et al., 2015). This ranked the region the last but one in the list of the then 21 regions of Tanzania Mainland. In 2012, the region realized less than 50\% of Millennium Development Goals (MDGs) which ranked it a poor performing in the country (Kumalija et al., 2015). Similarly, during the launching of the Results-Based Financing in the Tanzanian health sector, the region registered the lowest achievements in health service delivery (URT, 2015a). Among the six LGAs, Kahama Town Council, Shinyanga Municipal Council, Kishapu, and Ushetu District council in the region depicted similar performance levels with the region, hence they were selected for the study. These four local governments had a total of 1,340 employees working in the decentralized health facilities. Multi-stage sampling was used in drawing the sample. It commenced by stratification of the target population into eight strata of employees with resembling functions in each Local Government Authority. This facilitated to draw of the representative sample from each stratum (Kothari, 2004). The stratification of the target population is shown in Table 1. This was followed by the application of Yamane's formula (as quoted by Israel, 2013) $n=N / 1+N\left(e^{2}\right)$ at the confidence level of $95 \%$ to determine the sample size from 1,340 target population.

$$
\text { Whereby } \begin{aligned}
\mathrm{n} & =\text { Sample size } \\
\mathrm{N} & =\text { total population } \\
\mathrm{e} & =\text { degree of freedom } \\
\mathrm{N} & =1340 \\
\mathrm{e} & =0.05 \\
\mathrm{n} & =\mathrm{N} / 1+\mathrm{N}\left(\mathrm{e}^{2}\right) \\
\mathrm{n} & =1340 / 1+1340\left(0.05^{2}\right) \\
\mathrm{n} & =308
\end{aligned}
$$




\section{Mll Macrothink \\ Journal of Public Administration and Governance \\ ISSN 2161-7104 \\ 2020, Vol. 10, No. 2}

Table 1. Population and Sample Size

\begin{tabular}{|c|c|c|c|c|c|c|c|c|}
\hline \multirow[b]{2}{*}{$\begin{array}{l}\text { Stratified } \\
\text { HRH cadres }\end{array}$} & \multicolumn{4}{|c|}{ Target population } & \multicolumn{4}{|c|}{ Proportionate Sample } \\
\hline & $\begin{array}{c}\text { Shinyanga } \\
\text { DC }\end{array}$ & $\begin{array}{c}\text { Kishapu } \\
\text { DC }\end{array}$ & $\begin{array}{c}\text { Ushetu } \\
\text { DC }\end{array}$ & $\begin{array}{c}\text { Kahama } \\
\text { TC }\end{array}$ & $\begin{array}{c}\text { Shinyanga } \\
\text { DC }\end{array}$ & $\begin{array}{c}\text { Kishapu } \\
\text { DC }\end{array}$ & $\begin{array}{c}\text { Ushetu } \\
\text { DC }\end{array}$ & $\begin{array}{c}\text { Kahama } \\
\text { TC }\end{array}$ \\
\hline Officers & 7 & 6 & 7 & 18 & 2 & 1 & 2 & 4 \\
\hline Clinicians & 43 & 46 & 37 & 59 & 10 & 11 & 9 & 14 \\
\hline $\begin{array}{l}\text { Nurses } \\
\text { Medical }\end{array}$ & 74 & 112 & 122 & 261 & 17 & 26 & 28 & 60 \\
\hline $\begin{array}{l}\text { Attendants } \\
\text { Laboratory }\end{array}$ & 61 & 93 & 65 & 156 & 14 & 21 & 15 & 35 \\
\hline $\begin{array}{l}\text { Technologist } \\
\text { Rare }\end{array}$ & 11 & 16 & 17 & 30 & 3 & 4 & 4 & 7 \\
\hline professions & 4 & 4 & 4 & 9 & 1 & 1 & 1 & 1 \\
\hline Officers & 16 & 3 & 9 & 6 & 4 & 1 & 2 & 1 \\
\hline $\begin{array}{l}\text { Supporting } \\
\text { staff }\end{array}$ & 6 & 4 & 3 & 31 & 1 & 1 & 1 & 6 \\
\hline Total & 222 & 284 & 264 & 570 & 52 & 66 & 62 & 128 \\
\hline
\end{tabular}

Source: Human resource for Health in LGA- Seniority List, 2016

Based on the ealculated sample size, the proportionate sample size was calculated from each stratum to get the representative sample of 308 respondents as illustrated in Table 1. Thus, from each stratum, the proportional sample size was calculated by $\mathrm{x} / 1340 * 308$ ( $\mathrm{x}$ representing the number of human resources in the respective stratum). The proportionate sample size calculated in each stratum is as shown in Table 1. The questionnaires were distributed to 308 randomly selected respondents based on the seniority list as the sampling frame for each LGA. Out of 308 distributed questionnaires, 287 questionnaires were properly filled in and hence used for the study. The qualitative data was collected from 24 and 6 Focus Group Discussions (FGDs). The resourceful persons for the interview included health secretaries, in-charges of the district hospitals, health centers, and dispensaries in the study areas. Descriptive analysis was used for survey data complemented by the content analysis from interviews and FGDs.

\section{Results and Discussions}

The respondents were asked to show their level of agreement regarding performance appraisal aspects. The summary of the responses for each aspect of the performance appraisal is presented in Table 2 . 
Table 2. Respondents' Perceptions of the Performance Appraisal

\begin{tabular}{|c|c|c|c|c|}
\hline Performance appraisal Aspects & Low & Moderate & High & Mean(STD \\
\hline $\begin{array}{l}\text { I participate in setting the performance } \\
\text { standards }\end{array}$ & $67(23.3)$ & $12(4.2)$ & $208(72.5)$ & $3.68(1.183)$ \\
\hline I participate in setting evaluation criteria & $30(10.5)$ & $13(4.5)$ & $244(85)$ & $4.00(1.007)$ \\
\hline $\begin{array}{l}\text { I participate in evaluating my } \\
\text { performance }\end{array}$ & $56(19.5)$ & $13(4.5)$ & $218(76)$ & $3.82(1.171)$ \\
\hline $\begin{array}{l}\text { Performance evaluation results are } \\
\text { linked to HR practices such as } \\
\text { promotion and training }\end{array}$ & $149(51.9)$ & $53(18.5)$ & $85(29.6)$ & $2.58(1.268)$ \\
\hline $\begin{array}{l}\text { Feedback on performance evaluation is } \\
\text { timely provided }\end{array}$ & $170(59.2)$ & $35(12.2)$ & $82(28.6)$ & $2.49(1.319)$ \\
\hline
\end{tabular}

Source: Survey Data, 2017

Even though more than half of the respondents (72\%) and (76\%) revealed that there was high participation in setting the performance targets and actual performance evaluation, the exercise could hardly improve training and compensation for performance decisions. This is reflected by more than half of the respondents $(52 \%)$ who claimed that there was a low linkage between the performance appraisal results and human resource decisions. The high scores in setting performance standards, setting performance evaluations, and evaluation of the performance are linked to the Quality Improvement Teams (QITs). Similar findings were noted during the data collection in which several QITs were observed operating to realize the set team targets. Therefore, the findings imply that while team performance in health facilities at the study areas was evaluated, individual performance was ineffectively evaluated. The ineffective performance evaluation of the individual employee in the study areas is related to the ineffective application of the OPRAS. The qualitative findings revealed OPRAs forms are distributed to the employees to fill in their own and resubmit to the heads of the units. This was repeatedly raised during discussions by members in most of the Focus Group Discussion and supported by members that:

At the beginning of every financial year, we are supplied with the OPRAS forms to fill in our own. The filled OPRAS forms are submitted to the facility in-charge who resubmits them to the health secretary. At the end of the year, we are supplied with the OPRAS forms to fill the remaining parts and then resubmit them (Kishapu DC, February 2017).

Thus, although the employees fill in OPRAS forms, they do not abide by the procedural requirements, which call for jointly filling in the forms between the supervisor and the supervisee to create shared understanding regarding the performance targets, objectives, and resource requirements for performance improvement. In a similar vein, in one of the study councils, it was observed during data collection that the OPRAS forms were distributed in January 2017 instead of July 2016. During the distribution, the officer at the LGA headquarter insisted the facility in-charges ensure the forms are properly filled in by every employee and immediately resubmitted back to make them available during the inspection. 


\section{Mll Macrothink}

Journal of Public Administration and Governance

ISSN 2161-7104

2020, Vol. 10, No. 2

This indicates that OPRAS as an instrument for assigning responsibilities and assessing employees' performance in the decentralized health services in the country is ineffectively used. In some LGAs like this one, OPRAS forms are filled for the sake of showing the higher authority that employees adhere to the requirements and not for assigning responsibilities and assessing employees' performance. This is a clear indicator that the OPRAS instrument is ineffectively used in the study area and hence ineffective performance appraisal in the facility. Thus, even though the ineffective use of OPRAS in Tanzania public services is extensively documented by different authors and reports including Tefurukwa (2014) and CAG (2015-2018), the findings of this study explored the causes for ineffective use of the instrument in assessing employees' performance. The qualitative results revealed several factors hindering the effective use of OPRAS in assigning the responsibilities to supervisees and assessing their performance. The factors include difficulties in setting performance targets and its related evaluation criteria; inadequate human and financial resources; reluctance by supervisors and subordinates to use the OPRAS instrument; unavailability of the immediate motivation related to the appraisal results; the complexity of the OPRAS instrument; shortage of employees making them overwhelmed by their responsibilities, and the exercise being time-consuming.

\subsection{Implications of Performance Appraisal on Human Resource Decisions}

The manner in which performance appraisal is undertaken in the decentralized health facilities in the study area affects the human resource decisions including training and rewards. Generally, the findings imply that individual performance appraisal is ineffectively undertaken and hence the human resource decisions are not evidence-based. The subsequent subsections present specific implications for each human resource decisions and the basis upon which each is made.

\subsubsection{Implication of Performance Appraisal Practice on Training}

The findings in Table 2 revealed the ineffective appraisal of the individual employee's performance. Thus, findings imply that the training decision remains uninformed by the evidence. The results regarding the level of agreement by the respondents on each of opinion regarding how the training items are undertaken are summarized in Table 3.

Table 3. The Manner in which Training Aspects are undertaken

\begin{tabular}{lllll}
\hline Training Aspects & \multicolumn{1}{c}{ Low } & Moderate & \multicolumn{1}{c}{ High } & Mean(STD \\
\hline I always participate in TNA & $222(77.4)$ & $33(11.5)$ & $32(11.1)$ & $2.36(0.724)$ \\
Training is linked to TNA & $72(25.1)$ & $118(41.1)$ & $97(33.8)$ & $3.16(0.881)$ \\
$\begin{array}{l}\text { Selection criteria for HRH to attend } \\
\text { training is in place }\end{array}$ & $187(65.2)$ & $64(22.3)$ & $36(12.5)$ & $2.50(0.784)$ \\
$\begin{array}{l}\text { The facility training programme in } \\
\text { place }\end{array}$ & $176(61.3)$ & $72(25.1)$ & $39(13.6)$ & $2.55(0.796)$ \\
\hline
\end{tabular}

Source: Survey Data, 2017

Generally, the findings revealed that the majority of respondents $(77.4 \%)$ were of the views 
that there was inadequate employees' participation in training needs assessment (TNA). Likewise, more than half of the respondents $(65.2 \%)$ perceived that there were no clear selection criteria for employees to attend the training. Further, $61.3 \%$ of the respondents opined that in most cases facility training programmes are not in place in most of the health facilities. The qualitative data revealed that in other facilities employees are included in the training programme of the LGA at headquarter level. Nevertheless, rooms for employees' participation in designing the training programmes are in place. Likewise, the training programmes are hardly implementable due to inadequate availability of funds. While the resource is mentioned as an obstacle in implementing the training programmes, there are several short courses provided by the government in collaboration with development partners. This implies that such resources would have been used to implement the training programmes if consultation with the parent ministry was made before the designing of the training programme. This implies that apart from the failure of the facilities to effectively use OPRAS results, the training process is inherently ineffective. Thus, the failure of the health facilities to link the individual performance evaluation results and TNA on the training is contrary to ideal practices in preparing the training programme. Different scholars document the ideal process in preparing the training progammes. Among them include Zahra et al. (2014) and Hameed and Mohamed (2016) who provide that TNA in the training the cycle. Although it is not documented by these scholars impliedly the TNA has to be linked with the performance appraisal result as a means of identifying the specific employee's missing skills for performance improvement. Thus, the failure to prepare facility training programmes informed by the OPRAS and TNA results and the inherent weaknesses in the preparation of the training programmes makes training ineffectively address the individual employee's performance gaps for quality of health service delivery. Further, it should be made clear that the inadequate availability of funds for the implementation of the training programme should not deter the preparation of the programme. Normally, the resource should follow activities and not vice versa. Thus, the well-prepared training programme is construed as a tool for attracting and mobilizing resources for implementation.

\subsubsection{Implications of Performance Appraisal Practice on Compensation for Performance}

The findings in Table 2 revealed that the individual employee's performance is ineffective evaluated due to the ineffective use of OPRAS. Further elaborations regarding the respondents' level of agreement on the basis in which compensation for performance is made are summarized in Table 4.

Table 4. The Basis upon which the Compensation Aspects are Made

\begin{tabular}{|c|c|c|c|c|}
\hline Compensation Aspects & Low & Moderate & High & Mean(STD \\
\hline Promotion is based on merit & $170(59.2)$ & $82(28.6)$ & $35(12.2)$ & $2.26(1.120)$ \\
\hline $\begin{array}{l}\text { Appreciation/recognition for } \\
\text { performance is frequently provided }\end{array}$ & $144(50.2)$ & $42(14.6)$ & $101(35.2)$ & $2.88(3.383)$ \\
\hline $\begin{array}{l}\text { Poorly performing } \mathrm{HRH} \text { are rewarded } \\
\text { accordingly }\end{array}$ & $135(47)$ & $97(33.8)$ & $55(19.2)$ & $2.60(1.059)$ \\
\hline $\begin{array}{l}\text { Salary and other payments reflect } \\
\text { workloads }\end{array}$ & $237(82.6)$ & $15(5.2)$ & $35(12.2)$ & $1.86(1.063)$ \\
\hline $\begin{array}{l}\text { Incentives like EDA and on-call } \\
\text { allowance frequently paid to HRH }\end{array}$ & $229(79.8)$ & $20(7.0)$ & $38(13.2)$ & $1.83(1.108)$ \\
\hline
\end{tabular}


Source: Survey Data, 2017

Generally, more than half of the respondents (59.2\%) perceived that there was a low linkage between promotion and merit. Likewise, the majority of the respondents $(82.6 \%)$ confirmed that salary and other payments such as extra duty allowance and annual salary increments are inadequately linked to the workloads. This implies that employees' compensation for performance is susceptible to the supervisor's discretions. The findings are in line with the observations by Human Resource for Health Strategic Plan 2008-2013 (MoHSW, 2008) which documented that despite the institutionalization of OPRAS, the promotions of employees are made based on longevity of service. The reliance on the employees' longevity of services in awarding compensations for performance is an indicator of going back to the comfortable zone of the 1990s when a confidential appraisal system was a dominant means. It also implies that there is ineffective observance of Public Service Act No. 8, 2002, the Public Service Regulations of 2003 and the Government Standing Orders of 2009 which establish the meritocratic principle for compensating employees' performance in Tanzania public service (URT, 2002; URT, 2003: URT, 2009). Apart from the employees' longevity of the service being informally used as an alternative criterion for compensation for performance, there is no uniformity regarding the number of years one serves before being confirmed and promoted to the post as summarized in Table 5.

Table 5. The Number of Years Before Confirmation and Promotion

\begin{tabular}{|c|c|c|c|c|c|c|c|c|c|c|c|c|}
\hline \multirow{2}{*}{$\begin{array}{l}\text { Name of } \\
\text { LGA/ } \\
\text { years }\end{array}$} & \multicolumn{6}{|c|}{$\begin{array}{c}\text { Years for confirmation in } \\
\text { percentage }\end{array}$} & \multicolumn{6}{|c|}{ Years for promotion in percentage } \\
\hline & $>2$ & $2-4$ & $5-7$ & $8-10$ & $11-13$ & $<13$ & $>2$ & $2-4$ & $5-7$ & $8-10$ & $11-13$ & $<13$ \\
\hline TC & 56 & 35 & 4 & 2 & 2 & 1 & 0 & 22 & 35 & 23 & 3 & 17 \\
\hline $\begin{array}{l}\text { Ushetu DC } \\
\text { Shinyanga }\end{array}$ & 58 & 37 & 2 & 1 & 1 & 1 & 0 & 31 & 38 & 10 & 3 & 18 \\
\hline $\begin{array}{l}\text { DC } \\
\text { Kishapu }\end{array}$ & 63 & 30 & 3 & 2 & 1 & 1 & 0 & 22 & 65 & 4 & 3 & 6 \\
\hline $\mathrm{DC}$ & 62 & 28 & 5 & 2 & 1 & 2 & 0 & 5 & 36 & 3 & 11 & 45 \\
\hline
\end{tabular}

Source: LGAs Seniority List, 2016/ 2017

The results from the seniority list of the human resource for health in four LGAs indicated a lack of uniformities regarding the number of years one serves in the same grade before being confirmed to the post and promoted to a higher grade. For example, the majority of human resources get promoted after serving between 5 and 7 years in the same grade. In some cases, employees get promoted after serving in the same grade for over 13 years. The findings correspond with the findings by Hameed and Mohamed (2016) who documented the insignificant contribution of performance appraisal on the performance of Tiruchirapalli district hospital in India due to the inability to link the appraisal results with motivation. Similar findings were reported by Shahzad et al. (2008) that the failure to carry out merit-based performance appraisal detrimentally affects its contribution to performance. The findings of this study added to the existing literature by clarifying that the ineffective performance appraisal in the study areas is due to the infective application of OPRAS 
instrument. This is related to the complexity of the instrument, inadequate preparation during the introduction of the instrument, and inadequate commitment of supervisors and supervisees on the application of the OPRAS instrument. The ineffective employees' performance appraisal detrimentally affects compensation decisions because they are hard related to individual performance efforts.

\section{Conclusion}

We found that even though the team performance is evaluated through QIT, the individual employee performance is ineffectively evaluated. This is due to the ineffective use of OPRAS to evaluate individual employee performance. The ineffectiveness in OPRAS detrimentally affects the quality of human resource decisions including training and compensations. This, in turn, affects the expected accountability of the supervisees at the respective facility level and their responsiveness in service delivery. The ineffective use of OPRAS in the study areas is inhibited by the difficulties encountered in setting performance targets and its related evaluation criteria; inadequate resources allocation for setting achievable targets in OPRAS instrument; reluctance by supervisors and subordinates to use the system, and the complexity of the OPRAS instrument setting performance targets and evaluating performance. Apart from the failure to use OPRAS results in training and compensation decisions, this study found several weaknesses inherent in the decisions. The weaknesses in these decisions include inadequate employees' participation in TNA; inadequate linkage between TNA and training; salary and other payments inadequately linked to workloads, and the reliance on the longevity of services for compensation. To address these challenges and enhance the effective use of OPRAS, it is imperative to simplify the OPRAS instrument and customize it to suit health sector settings, provision of training on the application of OPRAS at the facility level, linking OPRAS results with the immediate rewards, issuance of circulars and guidelines on the use of the instrument requirements, requirements for frequently report on the progress and set mechanisms (software) to verify that OPRAS is effectively used and the human resource decisions are linked to OPRAS results. The recommended areas for further studies improve the application of performance appraisal include but not limited to widening the scope of the study to include other public service sectors and designing OPRAS instrument which minimizes the hurdles of its application.

\section{Acknowledgment}

We acknowledge the efforts of various people and organizations whose participation in the designing of the study, data collection, and analysis made possible to accomplish the study and hence publication of this paper. We would like to appreciate the permission granted by the University of Dodoma, the Permanent Secretary, President's Office, Regional Administration, and Local Government and the Regional Administrative Secretariat in Shinyanga Region, Tanzania for granting permission to undertake the study in the region. Likewise, we acknowledge and appreciate the participation of the council directors at Kahama Town council, Ushetu, Shinyanga, and Kishapu district councils in the study. Specifically, we thank the human resources at the district, health centers, and dispensaries at Kahama Town council, Kishapu, Ushetu, and Shinyanga district councils for the active 
participation during data collection.

\section{References}

Bowra, Z. A., Sharif, B., Saeed, A., \& Niazi, M. K. (2012). Impact of Human Resource Practices on Employee Perceived Performance in Banking Sector of Pakistan, African Journal of Business Management, 6(1), 323-332.

CAG (2014). Annual General Report of the Controller and Auditor General on the Audit of Local Government, unpublished report, Government Printers, Dar Es Salaam.

CAG (2015). Annual General Report of the Controller and Auditor General on the Audit of Local Government, unpublished report, Government Printers, Dar Es Salaam.

CAG (2016). Annual General Report of the Controller and Auditor General on the Audit of Local Government, unpublished report, Government Printers, Dar Es Salaam.

CAG (2017).Annual General Report of the Controller and Auditor General on the Audit of Local Government, unpublished report, Government Printers, Dar Es Salaam.

CAG (2018). Annual General Report of the Controller and Auditor General on the Audit of Local Government, unpublished report, Government Printers, Dar Es Salaam.

Greco, L. G. (2004). Oates' Decentralization Theorem and Public Governance. Ssrn, 3-4. https://doi.org/10.2139/ssrn.481562,Retrieved on 11th December 2013. https://doi.org/10.2139/ssrn.481562

Hameed, A., \& Mohamed, S. (2016). HRM Practices and Organizational Performance in Hospitals. Journal of Business and Management, 18(11), 34-41.

Haraisa, A. L. (2016). The Impact of Human Resource Management Practices on Innovation Performance : An Empirical Study on Jordanian Private Hospitals, 6(4), 185-195.

Israel, G. (2013). Determining Sample Size, the University of Florida.www.edis.ifl.edu.pdfiles/pd/pd00600, Retrieved on 18/4/2015.

Ivanyna, M., \& Shah, A. (2012), How Close Is Your Government to Its People? Worldwide Indicators.

Koethenbuerger, M. (2008). Revisiting the "Decentralization Theorem"- on the Role of Externalities, 1(1997), 1-7. https://doi.org/10.1016/j.jue.2007.10.001

Kothari, R. (2004). Research Methodology: methods and techniques, New Age International (P) Limited, Publishers, New Delhi.

Kumalija, C. J., Perera, S., Masanja, H., Rubona, J., \& Ipuge, Y. (2015). Regional Differences in Intervention Coverage and Health System Strength in, 1-14. https://doi.org/10.1371/journal.pone.0142066.

Martinez-Vazquez, J. (2011). The Impact of Fiscal Decentralization: Issues in Theory and Challenges in Practice. Economics Faculty Publications, (23). 
https://doi.org/10.1142/S1793993310000160, Retrieved on 2nd September 2014.

MoHSW (2008). Human Resource for Health Strategic Plan 2008 - 2013, Government Printers, Dar Es Salaam.

Oates, W. E. (2006). On the Theory and Practice of Fiscal Decentralization. Ifir Working Paper Series, 32.

URT (1998). Policy Paper on Local Government Reform, Government printers, Dar Es Salaam.

URT (2002). Public Service Act No.8 of 2002, Government Printers, Dar Es Salaam.

URT (2003). Public Service Regulations, 2003, Government Printers, Dar Es Salaam.

URT (2005). The Constitution of the United Republic of Tanzania of 1977, Government Printers, Dar Es Salaam.

URT (2009). Tanzania Standing Orders for Public Service, Government Printers, Dar Es Salaam.

URT (2011). Guidelines for Open Performance Review and Appraisal System, Government Printers, Dar Es Salaam.

URT (2013). Basic Facts and Figures on Human Settlements, 2012, Tanzania, Government Printers, Dar Es Salaam.

URT (2015a). Results-Based Financing, Government Printers, Dar Es salaam.

Werther W. B., \& Davis, K. (1987)."Personnel Management and Human Resources", McGraw Hill Book Company, New York.

Tefurukwa, O. (2014). The Paradox of the Nexus Between Employees' Performance Appraisal Scores and Productivity in Tanzania. International Journal of Social Sciences and Entrepreneurship, 1(10), 1-11.

Singh, N. R. (2016). The Impact of Human Resource Management Practice on Organisational Performance - A Study on Debre Brehan University, 643-662.

Shahzad, K., Bashir, S., \& Ramay, M. I. (2008). Impact of HR Practices on Perceived Performance of University Teachers in Pakistan. International Review of Business Research Papers, 4(2), 302-315.

\section{Copyright Disclaimer}

Copyright for this article is retained by the author(s), with first publication rights granted to the journal.

This is an open-access article distributed under the terms and conditions of the Creative Commons Attribution license (http://creativecommons.org/licenses/by/4.0/). 